be for doctors and midwives to spend more time and effort in educating pregnant women and their husbands, helping to ensure that most gain some idea of the main trends in medical advance, acquire a more scientific habit of thought, and can understand argument and discussion over controversial issues.

The public, often encouraged by ignorant and biased reports in the media, is not too well informed and may press the wrong sort of questions at the expense of more fundamental issues that may directly affect the lives and wellbeing of mothers and babies. Is it, for example, wise to press for a "natural" delivery at the cost of distended, bruised, and lacerated pelvicfloor muscles with tearing of urethral and bladder supports? A well-timed episiotomy or low forceps delivery under local anaesthesia may often spare mother and child a good deal of stress. Questions need to be asked when things go wrong: why was the pregnancy allowed to go so far beyond term with a difficult delivery or even loss of the child? Might the difficulties have been avoided by earlier induction of labour? Might not a breast abscess that developed three weeks after delivery have been avoided had more active treatment been given when the doctor's attention was drawn to the cracked, painful nipple four days earlier? Why was more positive action not taken over the raised blood pressure noted three weeks before the patient had a severe accidental haemorrhage and lost her baby?

Failure of communication is said, quite rightly, tn be a frequent cause of dissatisfaction among patients; but lack of knowledge of the realities is equally important. When defects are identified in the service they are more likely to be corrected in a spirit of good will and collaboration among patients, midwives, and doctors when all concerned are properly informed.

\footnotetext{
${ }^{1}$ Barron, S L, Thomson, A M, and Philips, P R, British fournal of Obstetrics and Gynaecology, 1977, 84, 401 .

2 Tew, M, New Society, 1977, 49, 120.

${ }^{3}$ Macintyre, S, World Medicine, 1977, 12, No 18, 17.
}

\section{Economies in management}

Managers are rarely popular, and since the reorganisation of the NHS in 1974 many doctors have felt that we have too many. So, not surprisingly, in the financial crisis of 1975 the Secretary of State asked health authorities to economise in the cost of administration as part of the overall examination of public expenditure. This September letter was followed in June 1976 by the management standstill, which required the cost of management in 1976-7 not to exceed the cost at March 1976. The circular $(\mathrm{HC}(76) 36)$ also asked each region and area to review its management organisation and staffing and report its proposals for 1977-9. In that context managers were defined at some length as including administrative and clerical staff in the general administrative grade and above; nursing staff at senior nursing officer grade or above; regional and area pharmaceutical officers; regional scientific officers; catering, domestic, and senior works staff. Dental staff spending over half their time in administration were also included, as were doctors in community medicine, though their particular problems in maintaining adequate recruitment were recognised.

In April 1977 came another circular, $\mathrm{HC}(77) 10$, which carried the exercise a stage further. It pointed out that in 1976 $£ 228$ million, or $6 \%$ of the total NHS budget, had been spent on management and announced the Secretary of State's intention to reduce management costs to $5.5 \%$ of the budget by 1980 . No big structural changes were envisaged--they would have to wait for the report of the Royal Commission on the NHS-but the Department of Health will consider merging health districts and establishing single district areas where there is local agreement in favour of such changes. Few would disagree with this approach. Clearly there is a strong case against making major structural changes now, before the Royal Commission has reported; yet at the same time the management problems of multidistrict areas are obvious, with area staff reduplicating the work of district officers. Where single-district areas can be established relatively easily it would be wrong to delay action unnecessarily.

Much of the reduction in management costs will come, however, from better housekeeping. Work can be rationalised so that fewer managers are needed without waiting for any major changes in the relations between districts, areas, and regions. Most such changes are intended to be achieved by natural wastage. The Secretary of State has apparently recognised that redundancies cannot be ruled out altogether, but we should not forget the turmoil of 1974 and its effect on morale and on recruitment.

Both circulars have acknowledged the special problems of doctors in community medicine. Between now and 1980 losses from retirement and other causes will exceed the number of suitably qualified potential recruits. The losses will not be uniform throughout the country, and in consequence the DHSS will control community medicine establishments and vacancies centrally-a reasonable decision provided the method used does not result in an undue proportion of scarce recruits ending up in the Department itself.

The latest circular on management costs, from Wales (WHC(77)33), shows that the planned ${ }_{2}^{1 \%} \%$ reduction in management costs will release $£ 800000$ a year, in Wales, to patient care. The gain in English regions will be comparable as they achieve managerial costs consistent with the new national policy. So all this should help reduce waste without creating so much uncertainty that the managers become less effective.

\section{Prolactin updated}

Prolactin is the hormone primarily responsible for the unique mammalian trait of lactation. Yet it was not generally accepted that it existed separately from growth hormone until 1970. Soon after the initial bioassay data ${ }^{12}$ radioimmunoassays were introduced ${ }^{3}$ which measured circulating concentrations of the hormone both specifically and sensitively. These techniques have led to an explosion in our knowledge of both its normal and pathological physiology. At present we know most about the part prolactin plays in controlling lactation and gonadal function, but undoubtedly there is much more to learn: in animals prolactin has been implicated in over 80 different actions. ${ }^{4}$

Circulating concentrations of prolactin increase from the 25th week of fetal life and are high at birth; they then fall to prepubertal levels by the sixth week of life. ${ }^{5}$ In men, this low prepubertal concentration is maintained throughout life, but in women prolactin secretion is increased in the presence of oestrogen, so that there is a rise during puberty and pregnancy and a return to prepubertal concentrations at the menopause. ${ }^{6}$ There have been reports of changes during the menstrual cycle, with a midcycle rise and then a secondary rise in the luteal 
phase, thus paralleling oestrogen secretion, ${ }^{7}$ but these changes have been denied. ${ }^{8}{ }^{9}$ Certainly they are not essential for normal gonadal function, for patients whose prolactin secretion is suppressed usually ovulate and may become pregnant. ${ }^{1011}$ There is a circadian rhythm of prolactin secretion in both men and women, and concentrations increase during sleep at night and fall again by morning. ${ }^{12}$

Even under basal conditions the secretion of prolactin is pulsatile, ${ }^{13}$ so that circulating concentrations fluctuate at intervals of a few minutes throughout the day. Prolactin is a stress hormone, ${ }^{1.4}$ and concentrations may rise after emotional or physical stress. These changes need to be borne in mind when assessing patients with infertility or menstrual disturbances. Some women seem to have pulsatile concentrations of circulating prolactin which vary above and below the upper limit of the normal range, and these minor changes may possibly alter gonadal function in the same way as persistently raised concentrations. Some women, however, seem able to have normally functioning ovaries despite mild hyperprolactinaemia.

There is also reflex stimulation of prolactin secretion. Suckling post partum raises the prolactin concentration for about 30 minutes, but we do not know the mechanism of this stimulus. It does not appear to be associated with psychological factors; anticipation of nursing is not associated with the release of prolactin in lactating women. ${ }^{15}$ It is probably a neural reflex associated with stimulation of the nipple and areola. Rises comparable with those seen after suckling may occur after manual stimulation in normal non-pregnant non-lactating women and even in men, ${ }^{15} 16$ and a neural reflex is certainly found in sheep. ${ }^{17}$ In mothers who do not breast-feed prolactin concentrations decline to the prepregnancy range within one or two weeks, while even in those who continue to feed the response to suckling declines after delivery, so that by three months post partum the basal prolactin concentration is back to normal and there may be no rise after suckling. ${ }^{18}$

The part played by prolactin in human mammary growth is uncertain. Growth and differentiation of human female breast tissue in culture require growth hormone, insulin, oestrogen, and progesterone, as well as prolactin. "' Prolactin alone cannot maintain milk secretion: just as with mammary growth, other hormones including insulin and growth hormone are needed. While no direct relationship has been found between prolactin release and milk secretion, prolactin is essential for this: reduction of serum concentrations by bromocriptine effectively suppresses puerperal lactation ${ }^{20}$ and galactorrhoea. ${ }^{10}$ On the other hand, the suppression of lactation by oestrogens does not lower prolactin-it antagonises the lactogenic activity at the breast of prolactin. ${ }^{21}$ This action of oestrogen explains why milk secretion begins only at the time of delivery despite the high concentrations of lactogenic hormones during pregnancy, for after delivery the fetoplacental secretion of oestrogens ceases while the concentration of prolactin (now unopposed) remains high.

Both normal and pathological hyperprolactinaemia are associated with anovulation and usually amenorrhoea or irregular cycles. High concentrations of prolactin are found in men and women with hypogonadism but why this is so we do not know. It used to be assumed that there was a reciprocal relation between the hypothalamic pituitary mechanisms controlling gonadotrophin and prolactin secretion such that when prolactin secretion was increased gonadotrophin secretion was reduced, and vice versa. ${ }^{22}$ This conclusion was based on work on rats, ${ }^{23}$ but there is no evidence for this relation in man; indeed, on the contrary, basal gonadotrophin concentrations and the pituitary gonadotrophin reserve are usually normal in patients with hyperprolactinaemia. ${ }^{10}$ On treatment with bromocriptine, when prolactin concentrations fall, the gonadotrophin concentrations do not rise.

Hyperprolactinaemia does seem to affect the ovary. If exogenous gonadotrophins are given to patients with hyperprolactinaemia there is a reduced steroid response which may be made normal simply by reducing prolactin concentrations. ${ }^{24}$ Raised concentrations apparently inhibit steroidogenesis by the ovary. There may be an additional central effect of prolactin, since the surge of luteinising hormone (LH) which succeeds oestrogen administration is suppressed in the presence of hyperprolactinaemia. ${ }^{25}$ Prolactin also appears to alter corticotrophin-dependent adrenocortical pathways in the human. There is direct evidence in rats that prolactin modulates the formation of steroids in the adrenal, but in man the evidence has mostly been derived by inference from hyperprolactinaemic patients. These patients often have an excess of adrenal androgens, and this may account for the mild virilism sometimes seen with hyperprolactinaemia. ${ }^{24} 26$

Prolactin has several actions in animals that have not been fully investigated in man. ${ }^{4}$ Thus it may have behavioural effects promoting maternal activity and increasing sebaceous gland growth and male sex accessory development. Prolactin also has an important osmoregulatory action in some animals, but, though injection of ovine prolactin into normal men decreases salt and water excretion, ${ }^{27}$ we do not know whether this has any physiological importance.

The action of bromocriptine in lowering circulating prolactin concentrations in hyperprolactinaemic gonadal failure has simplified its management. A recent observation that on near lifelong treatment some rats develop endometrial hyperplasia ${ }^{28}$ which may progress to malignant tumours deserves, however, to be interpreted with caution. G M Besser and his colleagues ( $p$ 868) have now reported a study in 88 women who have been treated with bromocriptine. They found no evidence of any endometrial hyperplasia, metaplasia, or neoplasia. The rat is a poor model from which to draw conclusions for man: chronic suppression of prolactin secretion in rats leads to anovulation without shedding of the endometrium and a state of oestrogen dominance with the associated consequence of endometrial hyperplasia, succeeded by metaplasia and neoplasia. By contrast, women treated with bromocriptine pass from a pretreatment anovulatory, usually non-cycling, state to regular menstruation with regular endometrial shedding. Far from inducing a state of oestrogen dominance in women, treatment with bromocriptine for hyperprolactinaemia enhances the production of progesterone, and Besser et al suggest that bromocriptine may actually protect hyperprolactinaemic women with menstrual abnormalities against cancer of the endometrium.

Frantz, A G, and Kleinberg, D L, Science 1970, 170, 745

${ }^{2}$ Forsyth, I A, et al, British Medical fournal, 1971, 3, 225.

Hwang, P, Guyda, H, and Friesen, H, Proceedings of the National Academy of Sciences of the United States of America, 1971, 68, 1902

${ }^{4}$ Nicoll, C S, Handbook of Physiology, section 7, vol 4, part 2, eds E Knobil and $\mathrm{L} \mathrm{H}$ Sawyer, ch 32, p 283. Washington, American Physiological Society, 1974.

${ }^{5}$ Aubert, M L, Grumbach, M M, and Kaplan, S L, fournal of Clinical Investigation, 1975, 56, 155.

${ }^{-}$Robyn, C, et al, Acta Endocrinologica Congress 1977, Lausanne, abstract No S16.

Robyn, C, et al, in Human Prolactin, eds J L Pasteels and C Robyn, p 167, International Congress Series No 308. Amsterdam, Excerpta Medica, 1973.

${ }^{\rtimes}$ McNeilly, A S, Evans, G E, and Chard, T, in Human Prolactin, eds J L Pasteels and Robyn, C, p 231, International Congress Series No 308. Amsterdam, Excerpta Medica, 1973. 
${ }^{9}$ Robyn, C, et al, in Prolactin and Human Reproduction: Proceedings of Serono Symposia, vol 11, eds P G Crosignani and C Robyn, p 71 . London, Academic Press, 1977.

10 Thorner, M O, et al, British Medical fournal, 1974, 2, 419

1 Thorner, M O, et al, British Medical fournal, 1975, 4, 694

12 Nokin, J, et al, British Medical fournal, 1972, 3, 561.

13 McNeilly, A S, et al, fournal of Endocrinology, 1974, 61, 301.

14 Noel, G L, et al, Journal of Clinical Endocrinology and Metabolism, 1972, 35,840 .

${ }^{15}$ Noel, G L, Suh, H K, and Frantz, A G, Fourth International Congress of Endocrinology, abstract No 256, ed R O Scow. Amsterdam, Excerpta Medica, 1972

${ }^{16}$ Kolodny, R C, Jacobs, L S, and Daughaday, W H, Nature, 1972, 238, 284.

17 Kann, G and Martinet, J, Nature, 1975, 257, 63.

18 Noel, G L, Suh, H K, and Frantz, A G, Fournal of Clinical Endocrinology and Metabolism, 1974, 38, 413.

${ }^{19}$ Contesso, G P, Ceriani, R L, and Nataf, B M, Fourth International Congress of Endocrinology, abstract No 265, ed R O Scow. Amsterdam, Excerpta Medica, 1972.

${ }^{20}$ Cooke, I, et al, Postgraduate Medical fournal, 1976, 52, suppl 1, 75 .

21 McNeilly, A S, Postgraduate Medical fournal, 1975, 51, 231.

22.2 Thorner, M O, Clinics in Endocrinology and Metabolism, 1977, 6, 201.

23 Ben-David, M, Danon, A, and Sulman, F G, Journal of Endocrinology, 1971, 51, 719 .

24 Thorner, M O, and Besser, G M, in Prolactin and Human Reproduction: Proceedings of Serono Symposia, vol 11, eds P G Crosignani and C Robyn, p 285. London, Academic Press, 1977.

25.5 Glass, M R, et al, British Medical fournal, 1975, 3, 274.

26 Bassi, F, et al, Clinical Endocrinology, 1977, 6, 5 .

27 Horrobin, D F, et al, Lancet, 1971, 2, 352.

${ }^{2 *}$ Griffith, R W, IRCS, 1974, 2, 1661.

\section{The time and place for digestive enzymes}

According to the simple scheme of digestion taught in the early stages of medical school physiology the pancreas secretes an active enzyme, trypsinogen, which is converted into the potent proteolytic enzyme trypsin within the intestinal lumen. Why this is so, and how the process occurs, are less often considered.

One obvious and desirable reason for the two-step mechanism is to prevent the pancreas from digesting itself. Another possible advantage is that this proteolytic mechanism may be activated at a precise time or in a particular part of the gut, as determined by the activating mechanism. It might also be possible for the degree of activation, as well as the time and place, to be changed if metabolic requirements or other aspects of digestion were altered.

Interest in the mechanism by which trypsinogen becomes active trypsin has recently been revived. The change is brought about by the enzyme enterokinase, a glycoprotein found in the small intestine both in duodenal juice and bound to the brush-border membrane. Some workers have thought that enterokinase may originate in goblet cells or Brunner's glands, ${ }^{1-3}$ but it cannot be shown there by immunological methods, ${ }^{4}$ and the weight of evidence indicates that it arises in those busy little structures, the microvilli or brush border of the intestinal epithelial cells (enterocytes). ${ }^{j-8}$ As with other digestive enzymes, ${ }^{9}$ the amount of enterokinase within the cell seems to increase as the enterocyte migrates from crypt to villus tip, but enterokinase differs from other enzymes in that its concentration is not reduced in the mucosa of patients with coeliac disease. ${ }^{2-3}$

More interesting, and potentially more important, is the apparent confinement of the enzyme to a very short segment of the intestine-the duodenum and first $15 \mathrm{~cm}$ of jejunum. ${ }^{4}$ Enterocytes of this segment are unlikely to be intrinsically different from those in the remainder of the gut, and Hermon-
Taylor and his colleagues ${ }^{4}$ suggest that enterokinase synthesis may be triggered off by changes in luminal concentrations of other digestive substances. Trypsin, chymotrypsin, or bileacids, which release enterokinase from microvilli, are all possible agents. ${ }^{610}$ Slight support for this hypothesis comes from the observation of enterokinase activity in a segment of mid-jejunum anastomosed to the biliary and pancreatic ducts after a Whipple's operation. ${ }^{4}$

Inevitably these observations raise as many questions as they tentatively answer. What happens to enterokinase when there is no trypsin secretion? Is trypsin output affected by enterokinase secretion? To what hormonal stimuli is enterokinase susceptible? Severe enterokinase deficiency has been reported in an infant, but do lesser degrees of deficiency occur, either primarily or secondary to other gut disease? Why are normal amounts of enterokinase present in the atrophic jejunum? There still remains much to fascinate us as the subtle integration of the digestive process is revealed and as we come to realise the complexity and interdependence of the feedback mechanisms that control normal digestion, absorption, and nutrition.

\author{
'Eggermont, E, et al, Lancet, 1971, 2, 369. \\ 2 Rutgeerts, L, Tytgat, G, and Eggermont, E, Gastroenterology, 1972, \\ $63,381$. \\ ${ }^{3}$ Woodley, J F, and Keane, R, Gut, 1972, 13, 900 \\ ${ }^{4}$ Hermon-Taylor, J, et al, Gut, 1977, 18, 259. \\ Lobley, R W, and Holmes, R, Gut, 1970, 11, 1059 \\ "Hadorn, B, et al, Lancet, 1971, 1, 165. \\ Nordström, C, and Dahlqvist, A, Lancet, 1971, 1, 1185. \\ Schneider, R, Troesch, V, and Hadorn, B, Biologie et Gastroenterologic, \\ $1975,8,11$ \\ ${ }^{9}$ Nordström, C, and Dahlquist, A, Scandinavian fournal of Gastroenterology, \\ $1973,8,407$. \\ 11) Nordström, C, Biochimica et Biophysica Acta, 1972, 289, 367. \\ $"$ Hadorn, B, et al, Lancet, 1969, 1, 812.
}

\section{Recovery patterns and prognosis in aphasia}

Quantitative and long-term studies of recovery of function are remarkably rare, so that the recent investigation of recovery patterns in aphasia in a large and relatively unselected group of patients by Kertesz and $\mathrm{McCabe}^{1}$ is both welcome and informative. The practical and methodological problems of studies of this kind are daunting-taxonomy, for examplebut Kertesz and McCabe had no illusions on this score: they regarded the conventional classification they used (Broca's, Wernicke's anomic, conduction, and global aphasia) as a simple tool of measurement that might not be accurate or sensitive enough to provide a reliable prognosis for the individual case. Their caution was more than justified in view of the changing pattern of linguistic deficit over time.

How, indeed, can long-term recovery most appropriately be measured? Kertesz and McCabe used modified subtests of the Boston aphasia examination, including fluency (number and type of utterances), comprehension (responses to questions and instructions), and repetition (of words and sentences). Some of their patients were tested repeatedly months and in some cases several years after onset. The resulting graphs presented a variety of patterns, but a fair proportion showed the expected curve, most improvement occurring ${ }^{1-5}$ within three months. The curiously flat graphs of some patients could probably be related to the fact that most of this 